\title{
Algunas reflexiones en torno a la III Jornada de Desarrollo Social \\ El gran caos del amor. Globalización y relaciones de género en Sonora
}

\author{
Felipe Mora Arellano*
}

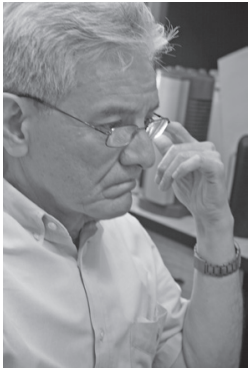

1 Sobre el título de la jornada. Se trata del título de un interesante libro de Ulrich Beck y Elisabeth Beck-Gernsheim: "El normal caos del amor. Las nuevas formas de la relación amorosa", publicado en español en 1998. En el prefacio al libro se indica que en él "se aborda el lado teóricosocial de lo que aparece como conflicto de relaciones amorosas".

En la obra se define: "El cambio actual como el paso de una situación donde la regla es la familia única para toda la vida, a otra donde se da un ir y venir entre diferentes familias temporales o bien entre formas de convivencia no familiares. No se da tanto la sustitución de una alternativa por otra, sino la coexistencia de una creciente diversidad de posibilidades. Cada persona construye, así, en interrelación con otras, su propio currículum. La autodeterminación de las mujeres en ese contexto representa un importante factor de cambio respecto de la situación anterior".

Se trata al amor como un logro de la modernidad y tiene como una de sus principales señas la emancipación frente a las reglas tradicionales de vida. Es decir, lo que antes se hacía sin negociar, hoy tiene que ser hablado, razonado, negociado, acordado y por ello, puede ser roto. En suma, el amor ha entrado en la dinámica de la democracia; se analiza y se asumen riesgos, pero no se escatima en romper la relación si es necesario.

\footnotetext{
* Licenciado y Maestro en Sociología por la Universidad Iberoamericana. Profesor de tiempo completo en el Departamento de Sociología y Administración Pública de la Universidad de Sonora. fmora@sociaels.uson.mx
}

2. Y sobre las relaciones de género y los nuevos y viejos arreglos en la entidad desde la visión de los hombres, que es el título de la mesa, habrá que decir que dichas relaciones son cambiantes y no caminan de manera homogénea en todos los campos (político, económico, jurídico, lingüístico, educativo, etc.). En algunos campos, como en la política, los hombres compiten con las mujeres y estas han ganado espacios de representación así sean pocos todavía; en la economía, hemos visto cómo las mujeres se han incorporado cada vez más al mercado laboral y compiten con los varones por posiciones en varias áreas. En la educación, especialmente en la superior, los hombres han dejado de ser predominantes en ciertas carreras y en otras son minoría. Podríamos hacer un recuento de todos aquellos espacios que eran propiamente masculinos y que ahora deben ser compartidos o competidos con las mujeres; en este balance habría que destacar cómo se "convino" o mediante qué arreglos y desarreglos, se tomaron los lugares, posiciones, roles, símbolos, términos, que antes pertenecían o se asumían como parte "natural" de los hombres.

3. Pondré un ejemplo que puede ser trivial, pero no tanto. El 16 de octubre de 2014 fue publicada, en todos los países hispanohablantes, la vigesimotercera edición del Diccionario de la Lengua Española. Una de las voces americanas que se ha incluido es la de amigovios, fusión de amigo y novio, y dícese de la "persona que mantiene con otra una relación de menor compromiso formal que un noviazgo". Cabe decir que en 2012 el matrimonio homosexual se incorporó al Diccionario y ahora lo hace la voz homoparental, que se aplica a "... una familia formada por dos personas del mismo sexo y los hijos".

4. Me detengo en la palabra amigovios. La aceptación por el Diccionario ocurre mucho tiempo después de que 
el término fue acuñado por los jóvenes. Yo lo escuché de mis estudiantes alumnas hace por lo menos una década, quizá más. Y según lo que entendí, cuando me lo platicaron, es que es un término que debe entenderse de manera situacional y transaccional; es decir, se negocia y acuerda qué se puede como pareja, hacer frente a otros como pareja y qué se puede hacer estando en privacidad. El punto era no perder una cierta autonomía o libertad para establecer más relaciones con otros y otras, hecho que limita el ser novios pues ello denota un sentido de pertenencia de ambos. Hay otros términos para expresar más o menos lo mismo, como "frees", "amiguitos", "amigos con derechos".

Cuando llegado el momento se decide vivir juntos, la opción de unión libre puede representar la mejor manera de convivir. En Sonora, en el año 2010, ${ }^{1}$ el 16.6\% de varones de 15 años y más estaban casados en unión libre, y el $21.6 \%$ de mujeres estaba en esa condición. En promedio, en 2010 es de $17.7 \%$, pero hace 20 años era de $9.7 \%$.

Es un hecho también que el matrimonio ya no está atado a la sanción cultural expresada en la frase "pobrecita, se le fue el tren", o las dudas sobre su orientación sexual para el caso de los varones. Así, en Sonora, el $54.2 \%$ de las mujeres de 15 a 29 años se mantienen en soltería; y el $68.2 \%$ de varones, está en esa condición.

1 Las cifras son del INEGI.
Hay una frase que leí no sé en dónde que dice: "Te amo a pesar del tiempo". ${ }^{2}$ Interpretada a mi manera querría decir que el tiempo mata el amor cuando este se rutiniza y no se cultiva, amén de otros factores, claro. Si partimos del supuesto de que la gente en su mayoría se casa por amor, en Sonora el amor dura 5 años o menos para el $30 \%$ de las parejas que estuvieron casadas, $18.4 \%$ de 6 a 9 años y $51.4 \%$ de 10 años o más. La duración media de los matrimonios que disolvieron su vínculo de manera legal fue de 12.1 años, 2 años más que en el año 2000.

Importante es señalar que las mujeres se divorcian más jóvenes que los hombres: $69.2 \%$ ellas frente a $60.4 \%$, ellos (de 15 a 39 años de edad). El 90.8\% de los hombres divorciados declararon tener trabajo frente al $62.3 \%$ de las mujeres. En 2011 todos los divorcios fueron judiciales, es decir, se tramitaron en los juzgados.

En Sonora, en 2011, de cada 100 enlaces ocurrieron 20 divorcios; en 1992 eran casi 8 de cada 100. Hay que observar que el número de matrimonios descendió en $16 \%$ de 2000 a 2011 y los divorcios aumentaron en $47.6 \%$.

${ }^{2}$ El número 5 de Cuadernos de Trabajo. Material didáctico para formar sociólogos (2009), colección que coordino, llevó por título: "Te amo a pesar del tiempo. Unas miradas al amor desde las ciencias sociales".

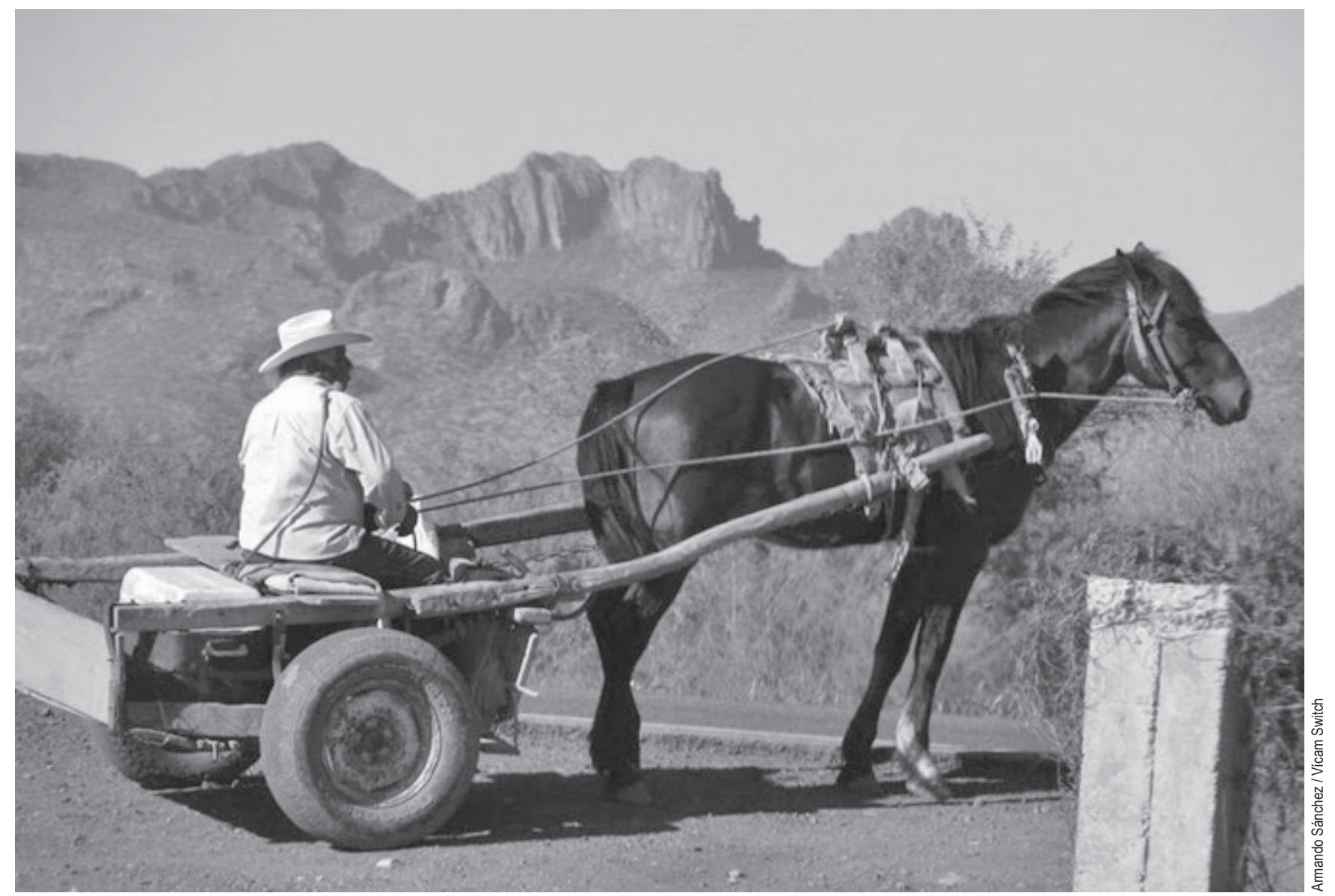

La bucólica estampa. Nada más bucólico y campirano que un hombre en su carreta con la sierra del Bacatete al fondo... Lo peor es que es real y convive con lo moderno, como puede verse por la cinta asfáltica bajo las patas del caballo (A. Valenzuela). 
La disolución del matrimonio, o sea el divorcio, suele calificarse como un indicador de que esa institución se está disolviendo y eso alarma a ciertos sectores de la sociedad y de la opinión escrita. Sin embargo, conviene asomarse a las cifras que indican cuántos hombres o mujeres vuelven a unirse. Por ejemplo, de las mujeres de 30 a 49 años, alguna vez unidas por situación conyugal actual (2009), según número de uniones, ocurre que las separadas de una unión libre o que han vivido en unión libre, tienden a contraer dos o más uniones; en cambio, las separadas de un matrimonio, en un $93.2 \%$ solo han tenido una unión.

5. No hay suficientes estudios que nos digan qué arreglos y desarreglos acomodan y desacomodan la vida amorosa en pareja. Con lo que contamos es con cifras que nos dicen que el $47 \%$ de las mujeres solteras de 15 años y más tuvo un incidente de violencia por parte de su última pareja, al $52 \%$ de las casadas y en unión libre les ocurrió lo mismo. Casi el $92 \%$ sufrió violencia emocional, casi el $54 \%$ violencia económica, casi el $15 \%$ sufrió violencia física, y $11 \%$ padeció incidentes de violencia sexual con su pareja. Amor apache, dirían algunos y algunas.

6. En la base de todo esto se asoma un elemento importante presente en las relaciones de género desde cuya perspectiva se pueden analizar nuestras relaciones sociales. Se trata del poder. Traigo a colación una vieja definición de ese concepto ofrecida por Max Weber, sociólogo alemán, que en este año se cumplen 150 años de su nacimiento.

La definición es esta: "El poder es la probabilidad de imponer la propia voluntad, dentro de una relación social, aún contra toda resistencia, y cualquiera que sea el fundamento de esa probabilidad".

Y enseguida una propuesta para reflexionar la definición. Las relaciones de género como relaciones sociales suponen una hegemonía masculina de diversos grados, en diversos campos, de diversas maneras, en diversos momentos. Cuando la hegemonía es plena, la resistencia es menor; cuando la resistencia aumenta, la hegemonía se convierte gradualmente en dictadura.

El proceso de resistencia puede ocurrir cuando se cuestionan las bases en las que se sustenta la probabilidad de imponer la propia voluntad; dicho cuestionamiento puede provenir de cambios en las condiciones estructurales que afectan las relaciones de género, necesariamente ligado con la toma de conciencia de que el poder no es natural ni congénito.

La brecha de género que se reduce en algunas partes del mundo y del país puede dar lugar al encuentro y a la negociación de los cambios de roles y al tránsito de una convivencia pacífica. Desafortunadamente, estamos presenciando que esta reducción representa una amenaza para el poder masculino. Hay en juego muchas cosas, entre ellas, el amor.

\section{Bibliografía}

Beck,Ulrich y Elisabeth Beck-Gernsheim. (1988). El normal caos del amor. Las nuevas formas de la relación amorosa. Barcelona: Paidós Contextos. El Roure.

Instituto Nacional de Estadística y Geografía (INEGI). (2013). Estadísticas a propósito del 14 de febrero, matrimonios y divorcios en México. Datos de Sonora. Recuperado de: http://www.inegi.org.mx/inegi/contenidos/espanol/prensa/ Contenidos/estadisticas/2013/matrimonios26.pdf

Real Academia de la Lengua Española. (2014). Diccionario de la lengua española. ( $23^{\mathrm{a}}$ ed.). Real academia española. Edición del tricentenario. Recuperado de: http://www.rae. es/sites/default/files/Dossier_Prensa_Drae_2014_5as.pdf

Weber, Max. (1977). Economía y Sociedad, vol. 1. México: Fondo de Cultura Económica, México.

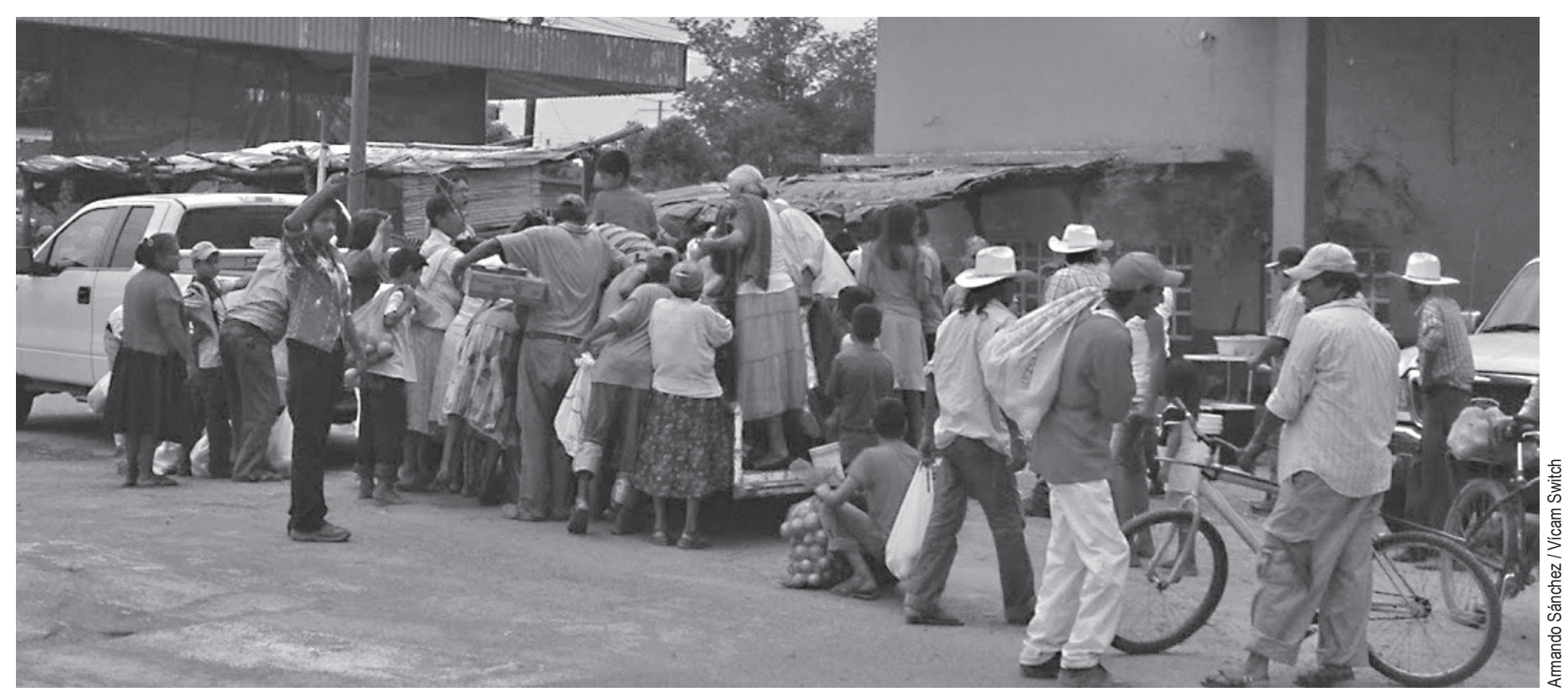

¡Hay Naranjas! Durante el bloqueo de la carretera internacional, los yaquis aportaron su fama y su presencia y los ricos de Obregón algunos víveres, como el diario carro de naranjas... mientras fue temporada (A. Valenzuela). 